\title{
Capital social e os fluxos migratórios internacionais de brasileiros
}

\author{
Wilson Fusco*
}

O processo migratório que conduz o brasileiro a viver e trabalhar em outros países é um evento que envolve, reconhecidamente, diversos riscos e desafios. As adversidades que surgem são resultantes, essencialmente, da frágil condição em que a maioria das pessoas se coloca, seja por permanecer e trabalhar no país escolhido sem o visto apropriado, pelo translado arriscado como o da fronteira entre México e Estados Unidos, ou ainda pelas diferenças culturais e linguísticas com o país de destino, igual ao verificado para aqueles que decidem viver no Japão. Por sua vez, uma das principais fontes de recursos para a organização dessas comunidades no exterior, o capital social, tem sido crescentemente utilizado como conceito para ampliar o conhecimento de processos característicos à migração internacional e da maneira como os migrantes lidam com as dificuldades em sua inserção no destino (FAIST, 2000).

O objetivo deste trabalho é analisar de que forma alguns aspectos da organização social das comunidades brasileiras nos Estados Unidos e Japão condicionam a inserção do migrante nesses países. Particularmente, estamos interessados em verificar determinadas práticas de utilização dos recursos que circulam por meio de laços sociais, em associação aos efeitos de expansão do movimento, adaptação do migrante no destino, e conexão entre pontos muito específicos na origem e no destino. Os dados primários apresentados para esta análise são provenientes de três surveys ${ }^{1}$ realizados em cidades de origem no Brasil, enquanto que as informações do censo do IBGE realizado em 2000 e os subsídios do Ministério das Relações Exteriores conformam os dados secundários utilizados.

*Demógrafo e pesquisador da Fundação Joaquim Nabuco. 


\section{Concentração no espaço}

Um dos efeitos mais visíveis do uso do capital social nas migrações é a concentração espacial dos grupos envolvidos, tanto na origem quanto no destino. Segundo as estimativas do Ministério das Relações exteriores para 2001, os principais países de destino dos brasileiros são Estados Unidos, Paraguai e Japão, que juntos agregavam $78 \%$ dos nossos emigrantes. Essa diminuta relação de países de destino tem uma correlação direta com a distribuição dos locais de saída no território nacional, pois cada movimento em direção a um destino particular guarda especificidades que condicionam o novo ingresso de um migrante em potencial no fluxo. Os brasileiros que vão para o Japão, por exemplo, saem principalmente do estado de São Paulo e do norte do Paraná, pois é lá que se encontra a maior colônia de descendentes de japoneses, condição suficiente para poder viver e trabalhar no Japão. O fluxo que leva ao Paraguai, por outro lado, está restrito ao entorno da fronteira com esse país, e está relacionado aos incentivos presentes na política de desenvolvimento agrícola do governo paraguaio (FUSCO e SOUCHAUD, 2008).

O movimento de brasileiros para os Estados Unidos, por sua vez, que não é afetado por recrutamento ativo, como no caso dos dekasseguis, e que não tem contiguidade com o território nacional, como os brasiguaios, é o movimento que apresenta a maior concentração de pontos de saída no Brasil. É essa característica tão específica de concentração, não só na origem, mas também no destino, que buscamos associar aos efeitos da utilização dos benefícios e restrições que transitam pelas redes sociais.

Apesar de ainda não podermos contar com o censo do IBGE para capturar informações necessárias à análise da emigração internacional, é possível utilizarmos uma variável associada a este tipo de migração para termos ideia da distribuição pelo território brasileiro dos migrantes que retornaram do exterior. Quando responderam em qual país estrangeiro residiam em sua última etapa migratória, os brasileiros residentes há menos de dez anos na localidade entrevistada configuravam-se como retornados do exterior. Dessa forma, os indivíduos captados no censo serão contabilizados como retornados para determinado município, mesmo que não tenhamos certeza de que tenham partido dali. Apesar dessa margem de incerteza, consideramos razoável a utilização dessa medida como uma aproximação para avaliarmos a participação das cidades brasileiras no movimento de emigração para outros países, particularmente para os Estados Unidos.

Dessa forma, podemos obter a quantidade de retornados do exterior que residia em determinado município em 2000. O número absoluto de retornados é uma boa medida para avaliar o volume de retorno, mas não para hierarquizar as localidades em função do impacto causado pelo volume de retorno na população. Para tanto, utilizamos uma medida que expressa a relação retornados/população total, tanto para municípios como para os estados nacionais. Esse procedimento posiciona, por exemplo, a cidade de São Paulo e seus quase 4 mil retornados no 
35 o lugar do ranking, enquanto que Governador Valadares, com somente 540 habitantes que voltaram dos Estados Unidos, fica registrado como o município que recebeu maior impacto proporcional de retorno (FUSCO, 2006).

Caso a distribuição de retornados fosse equilibrada, esperaríamos encontrar uma medida desse segmento proporcional à população de cada município, UF ou Região. No entanto, o reduzido número de municípios conectados com a migração para os Estados Unidos é uma característica marcante, evidenciada por diversas perspectivas. Em primeiro lugar, somente 10\%, ou 555 dos 5507 municípios brasileiros que existiam em 2000 registraram moradores residentes retornados dos Estados Unidos. A Região Sudeste, apesar de conter 43\% da população nacional, contava com $66 \%$ daquela categoria de migrantes. O Estado de Minas Gerais, que representava $10,5 \%$ da população brasileira, respondia por $21 \%$ dos retornados. Esses números confirmam a distribuição espacial desproporcional nos recortes territoriais estudados, o que está de acordo com a noção de circulação restrita dos elementos - positivos e negativos - que são normalmente associados às redes sociais.

Quando mudamos a escala de observação para o limite espacial das Unidades da Federação, constatamos mais uma vez que a grande maioria dos migrantes tem origem em um diminuto grupo de localidades: somente 64 municípios têm índice de retornados superior à média nacional; no estado de São Paulo, somente $17 \%$, ou 110 dos 645 municípios, têm retornados; em Minas Gerais, essa proporção é de 19\%. Esta última UF é a que mais se destaca com relação ao impacto da conexão de emigrantes com os Estados Unidos, pois exibe o mais alto índice dentre os contabilizados. Além disso, a maioria dos municípios com retornados está em Minas Gerais.

Essa concentração de locais de origem na migração para os Estados Unidos contrasta fortemente com a distribuição dos municípios envolvidos com o movimento em direção ao Japão. Apesar de reconhecidamente menor em volume do que o fluxo que leva à América do Norte, o registro de brasileiros retornados do Japão estava associado a $13 \%$ dos municípios do Brasil como local de chegada destes migrantes, medida proporcionalmente maior que os locais de retorno dos Estados Unidos. Ademais, outra perspectiva da distribuição espacial dos retornados do Japão amplia a ideia de concentração diferencial: o universo de municípios expostos ao risco de se envolver na migração Brasil-Japão se restringe majoritariamente aos locais onde existem comunidades nipo-brasileiras, e estas se concentram no estado de São Paulo e norte do Paraná, que, somados, respondem por $82 \%$ dos retornos. Em São Paulo, quase $50 \%$ dos municípios têm migrantes retornados do Japão; no Paraná, essa proporção é de $41 \%$, ainda que não existam comunidades de descendentes de japoneses na totalidade das cidades nesses dois estados, o que aumenta a expressividade desta medida. Esses números revelam uma característica importante deste movimento em particular, associada à distribuição da população nipo-brasileira pelo território nacional: a simples existência de descendentes de japoneses numa localidade determina uma alta probabilidade de encontrarmos retornados do Japão. 
Estimativas mais desagregadas sobre os brasileiros vivendo no exterior, elaboradas também pelo Ministério das Relações Exteriores, mostram a distribuição dessas pessoas internamente aos países de destino. Os limites territoriais correspondentes ao posicionamento dos brasileiros foram arbitrados em função da localização dos postos consulares, o que diminui a precisão quanto à distribuição dos imigrantes. Apesar disso, o fato de existirem oito postos nos Estados Unidos permite comparações entre as concentrações de brasileiros nas diferentes regiões desse país. As cidades de Nova lorque, Miami, Boston e Washington, por exemplo, agrupam quase $90 \%$ dos brazucas nesse país, revelando a costa leste dos Estados Unidos como a preferência nacional.

A maioria dos migrantes brasileiros que decidem viver no exterior, portanto, está distribuída entre bem poucos países e, no caso dos Estados Unidos, os migrantes se concentram na costa leste. Essa característica fica ainda mais evidente quando analisamos os fluxos originados nas cidades que participaram dos surveys, pois estas apresentam índices de concentração no destino ainda maiores: os Estados Unidos abrigam $86 \%$ dos migrantes valadarenses e $60 \%$ dos oriundos de Criciúma; esta cidade também apresenta fluxos relevantes para a Itália (14\%) e Portugal (11\%), relacionados à presença de descendentes de imigrantes italianos e portugueses em Santa Catarina; o Japão, sem surpresas, é o destino de praticamente todo descendente de japonês maringaense.

Os dados que mostram a distribuição dos migrantes nos estados norteamericanos e nas províncias do Japão reforçam nossa afirmação de que a migração de brasileiros para os Estados Unidos apresenta uma conexão muito estreita de algumas cidades na origem com pontos específicos no destino. Os migrantes de Valadares, por exemplo, situam-se principalmente em Massachusetts (52\%), Flórida (16\%), Nova Jersey (15\%) e Nova lorque (12\%), além de uma proporção mínima (6\%) que se dispersa pelos outros Estados; os criciumenses exibem uma concentração ainda maior, pois $83 \%$ dos que vão aos Estados Unidos ficam em Massachusetts, restando apenas $17 \%$ para serem contabilizados nos demais Estados; os migrantes que se dirigem ao Japão, por outro lado, apresentam uma concentração menor: 19\% em Shizuoka, 17\% em Aichi Ken, 14 províncias agrupando entre $6 \%$ e $2 \%$ dos migrantes, e todas as 47 províncias japonesas com alguma proporção de maringaenses.

A distribuição dos brasileiros pelas cidades dos Estados Unidos e Japão apresenta, também, um padrão de alta concentração para o primeiro país, e certa "diluição" dos migrantes no segundo. Boston agrega 38\% dos migrantes de Valadares e $59 \%$ dos oriundos de Criciúma, mas se levarmos em conta que Framingham, Somerville, e outras pequenas cidades com índices menores de imigrantes se localizam na região metropolitana de Boston, concluiremos que a concentração de brasileiros nessa região é ainda maior. Os migrantes que vão ao Japão, por outro lado, não se concentram de forma destacada em nenhuma cidade no destino. Ao contrário, encontram-se espalhados por 177 cidades, enquanto que os valadarenses alcançam um máximo de 61 e os criciumenses chegam somente a 35 cidades nos Estados Unidos. 
Como fica evidente, o deslocamento de brasileiros para os Estados Unidos tem um padrão muito nítido e particular na distribuição espacial da população migrante, tanto na origem quanto no destino. Encontramos muito poucos municípios no Brasil envolvidos com esse movimento, os quais se localizam, predominantemente, na Região Sudeste. Mesmo no interior de estados onde a emigração é mais intensa, como é o caso de Minas Gerais, a proporção de municípios vinculados a comunidades brasileiras no exterior não chega a 20\%. Para os Estados Unidos, os dados do Ministério das Relações Exteriores mostram a grande concentração de brasileiros na costa leste, e os resultados dos surveys apontam particularmente para o maior agrupamento de migrantes na Região Metropolitana de Boston, em Massachusetts. Os emigrantes de Governador Valadares evidenciam, com um histórico migratório mais antigo, como a lista de opções no destino diminui com o passar do tempo, concentrando-se em um número cada vez menor de localidades (FUSCO, 2002), e estreitando os laços com comunidades específicas. Como referência para comparação, vimos que os dekasseguis estão mais espalhados, tanto pelos municípios brasileiros como pelas cidades japonesas.

\section{Organização Social e Migração}

Antes de buscarmos elementos que contribuam para explicar o processo de ampliação da migração internacional, é necessário ressaltar que a maior parte dos recursos do capital social é disponibilizada localmente (FAIST, 2000). 0 conjunto desses recursos locais está conectado a interesses e normas sociais que, frequentemente, moldam o comportamento mais geral de todos os membros de qualquer sociedade. Tais bens, normalmente não-monetários, como informações importantes, favores, acesso a outros conjuntos de recursos por laços sociais fracos, circulam no interior de grupos sociais e entre esses grupos, cuja coesão, de maneira geral, depende da manutenção dos contatos entre os membros (MASSEY, 1998). Dessa forma, os laços pelos quais circula o capital social funcionam como "âncoras" que contribuem para que o indivíduo permaneça no mesmo ambiente, pois a proximidade espacial é um fator que contribui para a maior frequência de contatos entre os membros de cada grupo.

Quando alguns migrantes pioneiros se estabelecem em outro país, depois

de enfrentarem altos riscos e custos, tanto financeiros quanto emocionais, o primeiro estágio na formação de um fluxo maior de saídas é atingido. Para que o processo migratório evolua, no entanto, é necessário que tais pioneiros mantenham e cultivem os laços sociais com a origem. $O$ deslocamento de alguns migrantes e de suas redes pessoais para outra localidade, associado à ampliação dessas redes ao passo em que se estabelecem no destino, inicia o processo que pode levar à expansão da emigração, pois os demais membros do grupo original do migrante passam a ter mais e mais contatos no exterior, que se configuram como potenciais fontes de recursos (TILLY, 1990). Os laços de parentesco e amizade, nesse contexto, restringem a ampliação do movimento aos limites 
espaciais, geralmente estreitos, nos quais repousam esses laços. O aumento do alcance das redes sociais relacionadas à migração internacional, portanto, amplia a esfera de inclusão para potenciais migrantes, ao mesmo tempo em que limita esse crescimento ao local onde se encontram os grupos sociais na origem, vinculados aos respectivos membros no destino. Como consequência, somente alguns indivíduos de determinadas cidades podem alimentar e concretizar as expectativas de migrar com ajuda de terceiros para locais específicos, nos quais a clandestinidade é um fator limitante.

$\mathrm{O}$ que é necessário para que um indivíduo ingresse em um fenômeno de massa, especificamente no movimento migratório para os Estados Unidos? Por um lado, há que se considerar os riscos envolvidos no processo, como a possibilidade de prisão e deportação. Além disso, também devem ser levados em conta os custos emocionais e financeiros, como o distanciamento da família e dos amigos, e os gastos para financiar a viagem, pagar aluguel, sobreviver, enfim, até a obtenção de um trabalho remunerado. Por outro lado, o conjunto de recursos disponíveis no interior de grupos sociais que extravasam fronteiras nacionais, quando mobilizado eficientemente, atenua significativamente os riscos e custos para quem decide pela migração. Por meio de questões especificamente aplicadas à experiência do migrante, pudemos analisar os procedimentos utilizados para a consecução do plano de viver em outras terras.

O questionário aplicado em Governador Valadares difere levemente do modelo utilizado em Criciúma e Maringá. Em Valadares, por exemplo, foi colocado um quesito sobre quem o migrante conhecia no destino antes de sua primeira viagem. Em Criciúma e Maringá, por outro lado, essa questão foi modificada para apreender as fontes de recursos para hospedagem e obtenção de emprego no país receptor. Em ambos os casos, essa informação revela tanto a extensão dos laços sociais, que ligam origem e destino através das fronteiras nacionais, como a utilização do capital social que circula por esses laços.

Os resultados da pesquisa mostram quem o migrante conhecia no destino antes de sua primeira viagem: enquanto que $20 \%$ dos valadarenses declararam não conhecer ninguém no país de destino, mais de $56 \%$ tinham parentes e aproximadamente $24 \%$ tinham pelo menos um amigo aguardando sua chegada; nos poucos casos em que o migrante declarou ter ambos, parentes e amigos, no país receptor, o registro foi efetuado na conta dos parentes, o que explica parcialmente a maior frequência de respostas nessa categoria. Os laços de parentesco, no entanto, são reconhecidamente os mais importantes na migração a partir de Governador Valadares (ASSIS, 2004; SOARES, 2002; FUSCO, 2005).

A relevância dos grupos familiares na emigração valadarense, além disso, ganha força com o passar do tempo, como pode ser verificado a partir da desagregação dos dados coletados. Pelo histórico migratório mais antigo, o movimento de Valadares pode ser dividido em três períodos distintos: aceleração (de 1961 a 1986), clímax (1987 a 1989) e desaceleração e estabilidade (1990 a 1997). Podemos observar o decréscimo contínuo na proporção de indivíduos 
que não tinham nenhum conhecido no exterior, a qual corresponde a quase um terço dos migrantes na fase inicial, reduzindo-se a pouco mais de um décimo no último período. Ao mesmo tempo, a proporção de pessoas que tinham parentes nos Estados Unidos cresce de $45 \%$ na primeira fase para mais de dois terços no período mais recente. As conexões familiares aparecem em destaque no processo migratório que se amplia pela cidade, até o momento em que quase todos os potenciais migrantes tivessem pelo menos um parente ou amigo nos Estados Unidos. Essa dinâmica deixa clara, mais uma vez, a associação entre a expansão do movimento e a circulação do capital social entre os membros de determinados grupos de parentesco ou de amizade.

A origem dos recursos financeiros usados pelos valadarenses na preparação da viagem para os Estados Unidos, também foi estudada. Menos da metade dos migrantes contou somente com recursos próprios, enquanto que, dentre os demais, $40 \%$ solicitaram e receberam ajuda de parentes, $9 \%$ tiveram auxílio dos amigos, $4 \%$ recorreram às agências de viagens, e $2 \%$ tiveram ainda outra fonte de financiamento. Os serviços oferecidos pelas agências de viagens configuramse mais como arranjos institucionais do que sociais, porém as informações necessárias para sua utilização passam certamente pelas conexões sociais. Além disso, ressaltamos aqui que o dinheiro obtido dessa forma não é o bem do capital social que levamos em conta, mas o empréstimo na forma de favor, que guarda procedimentos de quitação diferentes daqueles utilizados pelas instituições financeiras.

Essas mesmas informações, agrupadas segundo o período da primeira viagem aos Estados Unidos, permitem uma visão dinâmica do uso do capital social. Ao mesmo tempo em que cai de forma contínua a proporção de pessoas que utilizaram somente recursos próprios, de $49 \%$ no primeiro período para $43 \%$ no período mais recente, o índice que mostra o auxílio financeiro oferecido por parentes cresce de $36 \%$ para $43 \%$. A importância que têm os laços familiares para um indivíduo decidido a migrar para os Estados Unidos é evidente, mas o principal efeito dessa forma de exposição dos dados é o de mostrar a relação entre a ampliação do movimento com o passar do tempo e a crescente utilização do capital social disponível, no processo migratório de Governador Valadares.

As questões sobre fontes de recursos financeiros e sobre ajuda para hospedagem e obtenção de emprego, aplicadas em Criciúma e Maringá, contêm a categoria "agência de recrutamento" entre as respostas. Ainda assim, foi incluída uma questão específica para sabermos se o indivíduo utilizou uma agência de recrutamento como seu principal expediente ao migrar. Os resultados obtidos deixam claro que esse não é o procedimento seguido pela maioria dos criciumenses, dos quais somente $7 \%$ se enquadram como agenciados, ao contrário daqueles originários de Maringá, que totalizam $71 \%$ nessa categoria.

Também foram incluídas questões que caracterizam os fluxos migratórios de Criciúma e Maringá de acordo com a condição de presença do migrante - retornado ou ausente (vivendo no exterior) - e o tipo de ajuda recebida em sua primeira 
viagem ao exterior. Ao declarar quem forneceu os recursos financeiros necessários e as informações sobre hospedagem e emprego, o migrante acaba revelando a teia de relações que liga origem e destino e que sustenta os fluxos migratórios. As categorias registradas indicam se o migrante recebeu a ajuda de parentes, amigos, agência de recrutamento ou se não recebeu qualquer tipo de auxílio.

Um dos mecanismos que promove a circulação do capital social é a reciprocidade como norma de comportamento, a qual pode ser específica ou difusa, conforme observamos em outro estudo (FUSCO, 2005). A ajuda para encontrar hospedagem, por exemplo, não necessariamente é fornecida pelos laços sociais fortes: se um parente fornece essa ajuda, ele pode hospedar o migrante em sua própria residência ou ainda fornecer informações ou indicações de possíveis locais, nos quais outros imigrantes devam algum favor àquele parente, ou ainda a outro imigrante (GRANOVETTER, 1983). O mesmo ocorre para a ajuda na obtenção do primeiro emprego. Essa troca de preciosas informações e favores, que ocorre por meio de laços fortes e fracos, é fundamental para aqueles que se encontram na situação de clandestino em outro país e, eventualmente, sem conhecimento do idioma local.

É justamente nesse momento que podemos perceber as diferentes estratégias dos migrantes de Criciúma e Maringá para realizar o projeto migratório. De acordo com as informações coletadas em campo, somados os migrantes que contaram com recursos financeiros de parentes e amigos, teremos $41 \%$ dos retornados e $51 \%$ dos ausentes. Pode-se dizer, então, que os migrantes de Criciúma costumavam utilizar os recursos financeiros disponibilizados pelas redes sociais de forma expressiva, em moldes semelhantes com o que também foi verificado no caso de Governador Valadares.

No quesito hospedagem, a utilização dos recursos do capital social é ainda mais intensa: $83 \%$ dos migrantes retornados e $92 \%$ dos ausentes conseguiram hospedagem graças a parentes ou amigos, enquanto que apenas $10 \%$ dos retornados e $8 \%$ dos ausentes não obtiveram qualquer tipo de auxílio nesse sentido. As agências de recrutamento estão presentes no projeto migratório de pouquíssimos migrantes criciumenses: $0,7 \%$ dos retornados e $1,2 \%$ dos ausentes recorreram a este tipo de serviço.

A obtenção do primeiro emprego no destino, no caso do fluxo que parte de Criciúma, é outro aspecto que chama a atenção quanto ao uso do capital social: $81 \%$ dos retornados e uma proporção semelhante dos ausentes conseguiram o primeiro emprego por meio de parentes ou amigos. Deve ser ressaltado aqui que, para todas as fontes de favores exibidas, os retornados utilizaram menos os recursos disponibilizados pelos laços sociais que os ausentes. Essa diferença pode indicar uma característica seletiva sobre aqueles que já são migrantes, determinando uma probabilidade maior ou menor de permanecer no destino ou de retornar ao Brasil.

O quadro em Maringá se mostra muito diferente da situação em Criciúma. Nenhum migrante da amostra utilizou recursos financeiros disponibilizados por 
amigos quando viajaram pela primeira vez ao Japão. Apenas $18 \%$ dos retornados e $16 \%$ dos ausentes recorreram ao auxílio de parentes. Em compensação, 52\% dos retornados e $64 \%$ dos ausentes obtiveram os recursos financeiros necessários para a primeira viagem por intermédio de agências de recrutamento. Nos demais aspectos, é também o auxílio prestado pelas agências de recrutamento que predomina no projeto dos migrantes que partem de Maringá: $59 \%$ dos retornados e $71 \%$ dos ausentes tiveram a hospedagem no destino providenciada por agências. O índice é ainda maior quando se trata do auxílio para a obtenção do primeiro emprego no destino: $69 \%$ dos retornados e $75 \%$ dos ausentes utilizaram as agências de recrutamento. Esses números indicam uma configuração oposta a do movimento analisado em Criciúma, onde as redes sociais de parentesco e amizade predominam na oferta de recursos: a ajuda necessária aos migrantes de Maringá tem origem nas agências de recrutamento, que programam desde o financiamento da passagem aérea até o emprego.

\section{Conclusão}

O que motivou a realização deste trabalho foi o intuito de reconhecer fatores influentes, de natureza não estritamente econômica, para os efeitos específicos que resultam da dinâmica desse processo particular. A adaptação do imigrante na sociedade norte-americana, as características de ampliação do movimento migratório, e a ligação tão estreita entre locais de origem e de destino, são elementos que estão associados ao modo com que a comunidade migrante se organiza socialmente. Dessa forma, buscamos nas trocas de favores as respostas que nos permitiram prosseguir sobre o terreno que as teorias econômicas não alcançam. $O$ que percebemos é que os indivíduos ingressam majoritariamente no movimento que leva aos Estados Unidos porque pertencem a determinados grupos sociais, sejam de familiares ou de amigos, os quais, excepcionalmente, transplantam um ou mais pontos de suas redes para esse país.

Quando os imigrantes já estabelecidos propiciam a circulação de certos recursos, os quais correspondem às necessidades conjunturais dos que acabam de chegar, as condições adversas são atenuadas, e o novo imigrante se adapta mais facilmente à nova realidade. As informações sobre transferências de recursos mostram claramente que a principal fonte de ajuda para os imigrantes são os favores obtidos por meio de laços sociais. Empréstimos diferenciados, acolhimento ou indicação para hospedagem, e preciosas informações sobre emprego, são benefícios mediados pelos mecanismos do capital social. Além disso, mostramos que as redes de parentesco são as mais importantes nesse aspecto.

Os benefícios obtidos por meio de favores passam por canais muito restritos. Inicialmente, poucas pessoas podem usufruí-los, exatamente porque poucos grupos têm acesso a contatos no exterior. Com o passar do tempo, o aumento do contingente de migrantes proporciona o aumento correspondente de grupos na origem com laços transnacionais. $O$ processo de aceleração do movimento 
ocorre de forma gradual, ao contrário do fluxo de dekasseguis, que se amplia como se estes respondessem a um chamado que atinge a todos. Para o caso dos brasileiros nos Estados Unidos, o extravasamento dos recursos do capital social leva certo tempo para atingir outros grupos, o que confere um fator limitante ao ritmo de expansão do movimento. Cadenciada, a ampliação da migração ocorre localmente, em função da circunscrição da base territorial na qual os laços sociais estão estruturados.

Devido à limitação espacial dos grupos sociais, a expansão do movimento ocorre primordialmente em territórios contíguos, como domicílios de uma mesma vizinhança ou bairro. Os imigrantes nos Estados Unidos, contudo, não pertencem necessariamente aos mesmos grupos em suas cidades de origem. Assim, podemos imaginar vários pontos nessas cidades a partir dos quais algumas manchas se espalham, correspondendo ao aumento do fluxo migratório. Por esse motivo, fica fácil entender porque somente algumas cidades brasileiras apresentam altos índices de migração internacional para os Estados Unidos, ao mesmo tempo em que um número ainda menor de cidades desse país aparece como local de destino.

\section{Nota}

1 - O survey realizado em Governador Valadares-MG, em julho de 1997, fez parte do projeto CNPq (MCT/FINEP/PRONEX) intitulado "Imigrantes Brasileiros nos EUA - Cidadania e Identidade"; os surveys realizados em Criciúma-SC e em Maringá-PR, em junho de 2001, foram financiados pelo projeto FAPESP "As redes sociais nas migrações internacionais: os migrantes brasileiros para os Estados Unidos e Japão". Todos os projetos foram coordenados pela Profa. Dra. Teresa Sales.

\section{Referências}

ASSIS, Gláucia O. De Criciúma para o mundo: rearranjos familiares e de gênero nas vivências dos novos migrantes brasileiros. Tese de Doutorado em Ciências Sociais, IFCH-UNICAMP, 2004.

FAIST, Thomas. The Volume and Dynamics of International Migration and Transnational Social Spaces. Clarendon Press, Oxford. North Yo-rkshire, 2000.

FUSCO, Wilson. Redes Sociais na Migração Internacional: o caso de Governador Valadares. Textos NEPO (UNICAMP), Campinas-SP, v. 40, 2002, p. 1-96.

FUSCO, Wilson. Capital Cordial: a reciprocidade entre os imigrantes brasileiros nos Estados Unidos. Tese de doutorado em Demografia, IFCH/Universidade Estadual de Campinas, 2005.

FUSCO, Wilson. Conexão origem-destino: migrantes brasileiros no exterior. In: XV Encontro Nacional de Estudos Populacionais, 2006. Caxambú-MG. XV Encontro Nacional de Estudos Populacionais: Desafios e Oportunidades do Crescimento Zero, 2006.

FUSCO, Wilson; SOUCHAUD, Sylvain. La continuité migratoire a partir de l examen de la distribution géographique des retours brésiliens. Caravelle (Toulouse), v. 91, 2008, p. 17-47.

GRANOVETTER, Mark. The strength of Weak Ties: A Network Theory Revisited. Sociological 
Theory, no1, 1983, p. 201-233.

MASSEY, Douglas S. et al. Worlds in Motion: understanding international migration at the end of the millennium. Clarendon Press: Oxford, 1998.

SOARES, Weber. Da Metáfora à substância: redes sociais, redes migratórias e migração nacional e internacional em Valadares e Ipatinga. Tese de doutorado em Demografia, Universidade Federal de Minas Gerais, CEDEPLAR, 2002.

TILLY, Charles. Transplanted networks. In: YANS, M. V. (org.) Immigration reconsidered: history, sociology, and politics. Nova York: Oxford University Press, 1990.

\title{
RESUMO
}

A migração de brasileiros para o exterior é um processo que se baseia fortemente na organização social dos grupos envolvidos. Utilizando dados primários provenientes de pesquisas de campo por amostragem aleatória e dados secundários de outras fontes, este trabalho pretende evidenciar a importância do capital social entre brasileiros, a partir de uma comparação entre dois locais de destino: Estados Unidos e Japão. Dentre outros aspectos, a análise privilegia a associação entre a disponibilidade e uso dos recursos do capital social e a distribuição dos migrantes brasileiros em território nacional e estrangeiro.

Palavras-chave: distribuição espacial; migração internacional; capital social.

\begin{abstract}
The migration of Brazilians to other countries is a process deeply based on the social organization of involved groups. Using primary data from representative surveys and secondary data from other sources, this paper aims to highlight the importance of social capital among Brazilians migrants, comparing the outcomes of two different reception countries: United States and Japan. Among other things, the analysis focuses on the association between the availability and use of social capital resources and the spatial distribution of Brazilian immigrants.
\end{abstract}

Keywords: spatial distribution; international migration; social capital. 
